\title{
An Innovative Change in Technology Integration: Training Pre-Service Kindergarten Teachers to Be Courseware Designers
}

\author{
Chien-Heng Lin \\ Department of Early Childhood Education, Asia University, Taichung City, Chinese Taipei \\ Email: chienlin@asia.edu.tw
}

Received September $2^{\text {nd }}, 2012$; revised October $1^{\text {st }}, 2012$; accepted October $15^{\text {th }}, 2012$

\begin{abstract}
This study focuses on exploring whether pre-service kindergarten teachers can be trained to be designers of digital courseware through learning a series of technology training courses in a limited period of time during their teacher training program. The results show that preschool pre-service teachers can become courseware designers and have the capacity to integrate and produce multimedia courseware in their classroom teaching. This study also demonstrates an adequate training course and pattern for training teachers to be courseware producers, which can be referenced by other teacher training institutions.
\end{abstract}

Keywords: Courseware Designer; Kindergarten Teacher; Pre-Service Teacher; Professional Development; Technology Training

\section{Introduction}

The integration of multimedia technology in education has been applied pervasively in different level of teaching and learning and has become an inevitable component in many recent educational reforms. Due to the rapid development of computer technology, a plethora of computer courseware designed to assist learner's learning and teacher's teaching has been developed. Researchers have asserted that computer courseware can provide students with a more flexible, diverse, friendly learning environment and present a logical situational layout and an easy learning interface design (Tsai, 2010). Digital multimedia materials allow teachers to teach more vividly and attractively, and can also demonstrate objects or scenes which cannot easily be brought into the classroom (Volman, 2005).

Although multimedia technology has many advantages in teaching and learning, still not many teachers have applied this technology in their classrooms. According to Wozney, Venkatesh and Abrami's (2006) investigation, most teachers use computer technology to implement information searching, word processing and documenting, which are individual usages. Palak and Walls (2009) and Culp et al., (2005) also reported that teachers mainly apply computer technology for dealing with documental and communicational work, only less for instructional use, with no mention of creating digital teaching aids. One of the main reasons cited for this is the teacher's experience of using digital media. As Sime and Priestley's (2005) statement, teacher's experience of using digital technology can predict whether teachers will apply digital technology in their future classroom teaching. Especially for new teachers; their digital technology competency and experience tremendously influenced the integration of digital technology in their future classroom teaching (Slaouti \& Barton, 2007).

Many researchers advocate that teacher's integration of computer technology in classroom teaching is influenced by how much they have been trained (Baylor \& Ritchie, 2002; Galanouli, Murphy, \& Gardner, 2004). Teacher's competency and experience of using digital technology are mostly learned and enhanced during their teacher training courses. However, most of the teacher training institutions could not supply sufficient digital technology practice, and only teach them how to use the published multimedia materials (CD-Rom and DVD) or to use presentation functions such as Microsoft PowerPoint. Consequently, it is very rare for teachers to obtain advanced training courses which allow them to learn how to make multimedia teaching aids or courseware by themselves.

Therefore, we realized that teachers may only have very limited capacity for using digital technology. Although teachers may receive some computer enhanced classes and may obtain some knowledge of digital technology, they still lack confidence and ability in the practical application and are only confident in using a few basic skills (Galanouli et al., 2004). As a result, many teachers choose to adopt the published digital teaching material to be their integration tool, such as CD-ROMs or websites, due to their convenience. However, these digital products may not exactly match teacher's teaching needs or the teacher can only use part of the packaged material. Teachers may need to spend a lot time to reorganize the material. Also, the cost of the published digital material may be high and not affordable all the time. Besides, for teachers to search for appropriate digital teaching products is very time consuming, which may reduce teacher's willingness to integrate digital technology into classroom teaching.

To solve the problems, we may rethink the role teachers should play in technology integration. The teacher's role should be transformed from not only being the users but to be the designers, producers and implementers. Due to the rapid development of computer technology, it has become easier to access and operate digital technology than before. To design and make digital material it is not necessary to have an understanding of computer programming. Teachers can easily become producers of digital material and courseware through using the multimedia computer software, such as Adobe Flash. Once teachers have the capacity to design and produce their own digital material, it will be very helpful for them to integrate digital technology into classroom teaching effectively and fulfill their 
teaching needs.

Many researchers suggest that technology integration must take into account teachers' specific habits and needs in the application of technology (Becker, 2000; Harris, 2005; Wilson, 1999). If teachers can design and manipulate courseware by themselves, the digital products will be more suitable for teacher's actual needs and habits.

However, it will not be possible to develop a teacher's competency in designing and producing digital courseware in just few hours training or few days of workshops. The training plan has to be competently developed. It is necessary for teachers to have long term training to develop the capacity of using digital software and making digital courseware. Therefore, during teacher-training in the college pre-service teachers have to learn all the technologies and multimedia skills. This will enable them to be able to easily integrate multimedia into classroom teaching and allow them to effectively design appropriate digital courseware. The present teacher training institutions in Taiwan have insufficient arrangements for technology training for pre-service teachers to allow them improve their capacity for using digital technology. It has become essential for teacher training institutions to arrange complete courses to train preservice teachers in the design of digital courseware. This study focuses on exploring whether pre-service teachers can be trained to be courseware designers through learning a series of multimedia software and exploring the process of what they have gone through during their training and exhibiting their work at the end.

This study aims to explore how pre-service teachers can develop their competency in multimedia technology and be trained to be courseware designers in a series of training courses in the teacher-training institutions. We explored teachers' whole learning process, including their perspectives at the beginning, middle, and after their the training; the challenges they encountered, and discussed their learning results; thus trying to build a framework for teacher's technology training in teacher training institutions.

\section{Methodology}

\section{Research Background}

The background of this study was based on one teacher training institution in Asia University, located in the middle of Taiwan. This institution trains university students to be early childhood educators as well providing some professional projects for the purpose of enhancing pre-service teachers' professional ability in various aspects related to early childhood education. One of the training projects is digital courseware design which intends to train pre-service teachers to be familiar with applying multimedia technology in teaching and to develop as courseware designers.

\section{Training Courses}

In order to allow pre-service teachers to learn sufficient computer competency, a committee for deciding the curriculum was involved with two multimedia and three early childhood professors in Asia University. Through their discussions and analysis, a few indispensable aspects for manipulating multimedia courseware were identified, which included computer graphics, image processing, 2D animation and interactive interface design. Based on this curriculum, we expect to develop students' ability to be able to manipulate multimedia software and create digital courseware. Three training courses were decided upon by the committee; these included digital graphics and image processing, two dimensional animation, and digital courseware design. According to the complexity and learning sequence, the three courses are divided into two semesters and each lesson plan was discussed by the committee. Each course has its own learning objectives to reach and a final task to be completed by the end of the course. These final tasks will be such as creating a digital picture story book at the end of the course of digital graphic and image processing course, and an animation story picture book at the end of the course of $2 \mathrm{D}$ animation course. At the end of the whole training program, students will be requested to design and complete a CD-ROM courseware which has to include items of instruction, drill, evaluation and games; in a similar manner to a published teaching CD-ROM available on the market.

Some relative multimedia design theories and principles will be enhanced in the lessons, such as multimedia cognitive theory (Mayer, 2005; Mayer, Heiser, \& Lonn, 2001). Models and principles for integrating computer technology in teaching will be introduced as well, such as ADDIE (Analysis, Design, Develop, Implementation, Evaluation) (Dick \& Carey, 1996), the ASSURE (Analyze learners, State the objective, Select method, Require learning participation, Evaluate and revise) (Heinich, Molenda, Russell, \& Smaldino, 2001), the WebQuests (Introduction, Task, Information Sources, Process, Evaluation, Conclusion) model (Dodge, 1997), and the PLTRSAR (Problem statement, Learning objectives, Technology required, Rationale, Strategies, Assessment, Reflection) model (Wang \& Woo, 2007).

\section{Participants}

The choice of the participants represents purposive sampling and included thirty-six pre-service teachers from the school of early childhood education who, in their third year of university, had chosen the digital courseware design course. At the beginning of the course participants were informed of their participation in this study and their agreement was sought and received. This training project was designed to improve pre-service teachers' ability in using multimedia software and courseware design and extended over two semesters, with three professsional digital training courses.

\section{Data Gathering and Analysis}

The data reported in this study were collected with qualitative methods. The researcher uses various methods of qualitative data collection, such as participated observation, group interview, individual depth interview and analysis of students' portfolios and works, as the tools to record and investigate both the student's perspectives and the entire learning process. The data content included students' initial perspectives on joining the training course, the learning process, the difficulty of learning, their learning achievements, students' learning portfolio, and their final perspective of the entire training project. The whole period of the training course, one year, was recorded and the students' inner perspectives from the beginning to the end of the training was examined. The students' progress was recorded during different stages of learning. The research method of grounded theory was adopted as the data analysis method. 
Through a series of analysis steps grounded theory allows the data to be analyzed systematically from the raw data corpus, codes to be generated and some initial low level concepts to be built. Thus gradually we may develop some more abstract themes and then substantive theories are constructed in the final stage (Denzin \& Lincoln, 1998). Two core analysis concepts, constant comparison and theoretical sampling, were adopted for the data analysis.

\section{Result}

The results show the entire process of pre-service teachers' training of multimedia technology. Based on a long term collection of the qualitative data, we analyzed and classified the process into six significant stages, which are: the initial perspective of learning multimedia technology, the learning of fundamental technology (manipulate digital images), the learning of advanced multimedia technology (design animation and interactive interface function), integration with preschool curriculum, actual production of multimedia courseware, and finally the reflection of the whole training course.

\section{Student-Teacher Initial Perspective of Learning Multimedia Technology}

Before the start of the training course we investigated student-teacher perspectives on learning multimedia technology. Many students commented that the reason they selected this module is that they believe it will improve their professional development and bring a positive effect to their future occupation. One of the teachers stated:

Due to the high development of technology, using digital courseware to assist classroom teaching is an essential trend. If I can learn the skills for creating digital courseware, it will be very helpful in improving the various professional capacities which I may need in my future work.

Most of the teachers claimed that they are quite interested in learning new technologies and are willing to take the challenges.

I think that I am quite confident to deal with computer software because we have to use computers to do a lot of work every day. To learn computer multimedia software, such as Adobe Illustrator, Photoshop or Flash, should be very interesting. I look forward very much to learning it.

Students seem to be clear about what they are going to learn, but still feel some ambiguity over the detail. In addition, some students expressed their anxiousness about learning new technology and suggested that the teacher presents the material in a simple way and slows down the teaching schedule. The lecture responded:

I understand clearly they are kindergarten pre-service teachers. It is normal for them to feel a lack of confidence and be anxious about learning multimedia technology. However, the present multimedia software has become very easy to use. There is no need to write a computer program. The material can be created with just a click of the mouse button on the screen. Therefore, I encouraged them in the beginning of the course by saying that once you can use Microsoft Word for word processing, you will have no problem in manipulating this multimedia software.

In brief, before joining this training module, pre-service teachers may have some initial concerns about learning new technology. However, most of the students' perspectives in partici- pating in this training course are positive and full of expectation. The teachers also encourage them to take this challenge and persuade them that they have the potential to complete this training successfully.

\section{Learning Basic Skills of Computer Graphics and Image Processing}

In this stage, we focus on training students to be familiar with using fundamental multimedia software, such as computer graphics and image processing. We used the computer software Adobe Illustrator CS3 and Photoshop CS3, which were provided by the university computer center, to train students to do computer vector graphics, phantom editing, and some simple 3D graphics.

Initially the teachers were introduced to the various kinds of graphic tools and skills; and by the middle of the semester they were requested to create a digital image based on a particular topic; in the final part of the course students learned how to design an electronic picture book and had to complete a whole digital story book for their final evaluation, which is shown as Figure 1.

At this stage, many students showed a high interest in their training and demonstrated that they could accomplish every task requested by teacher. They show great sense of achievement when they presented their work to others. As one of the pre-service teachers reported:

I think this course is quite challenging. I spent many nights and a lot of energy on practicing and doing the homework. However, it is very interesting for me to do so and I overcame most of the difficulties when I engaged in doing the homework. It was a little bit time consuming, but I am quite satisfied with my learning and my piece of work.

Another student also comments:

I am quite confident with my ability to deal with computer graphics and image editing. Once I have to apply it in my future work, I will feel comfortable and not worried about it.

The teacher also comments about students learning at this stage:

We have good interaction during the classroom teaching and I can tell they do have pay a lot of attention during this course. Although they are not familiar with technology, they can achieve my targets and produce many excellent works in their final homework.

In this fundamental stage of learning, students show great

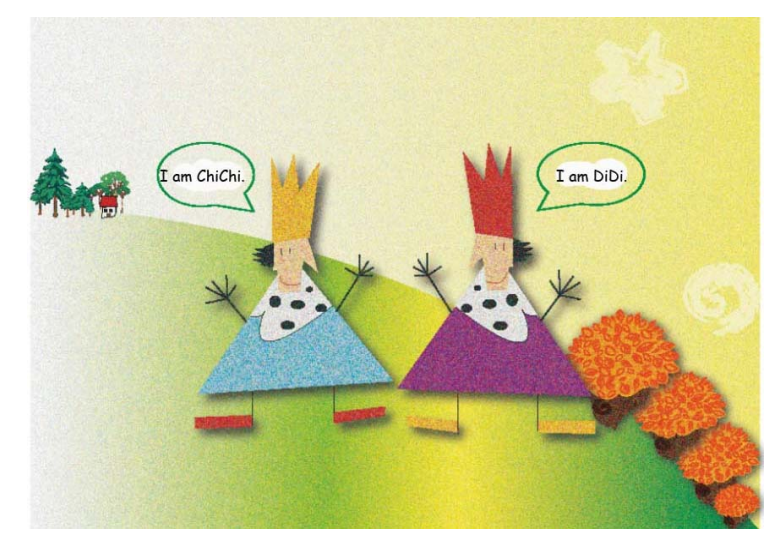

Figure 1.

A digital story book made by one of the participants. 
confidence and interest in being involved in the course and most of them can reach the teacher's standard educational targets.

\section{Learning Advanced Skills, Animation and Interactive Design}

After becoming familiar the fundamental skills of producing and editing digital images, the students are equipped for learning and developing their animation skills. At this stage students start to learn how to make 2D animation and design a story animation, which is shown as Figure 2. The computer software Adobe Flash was used to make animation. At the end of the course students were asked to transform a picture book to an animation. In this work, firstly, they had to apply the image process to cut down the characters and backgrounds from the picture story book; secondly, they then needed to make the characters move using their animation skills with animation software; thirdly, they had to add the subtitles, asides and the background music with the same software. During these processes of learning and practicing, they developed a lot of skills and acquired a lot of knowledge about creating animation as well as other digital materials. As one of the students shared her perspective in this stage:

To do picture book animation is a very challenging task for me, it is an integrative work, it has to combine computer graphics and image processing and transform digital material into vivid animation with animation software. In the beginning, my animation did not look very harmonious. However, through the teacher's advice I have made some modifications and my work improved a lot, and the final piece of work is really awesome. Although to complete this task is really time consuming and needed a lot of effort, I did overcome all the obstacles and completed my first work of story book animation. I am so happy with that.

\section{Learning How to Integrate in Classroom Teaching}

The design of the digital courseware has to fulfill the needs of the actual classroom teaching and should be easy for teachers to operate. In order to train students to design an appropriate digital courseware suitable for teachers' needs, students were asked to go into a kindergarten classroom to do observation for one week. During this week they had to observe and record the

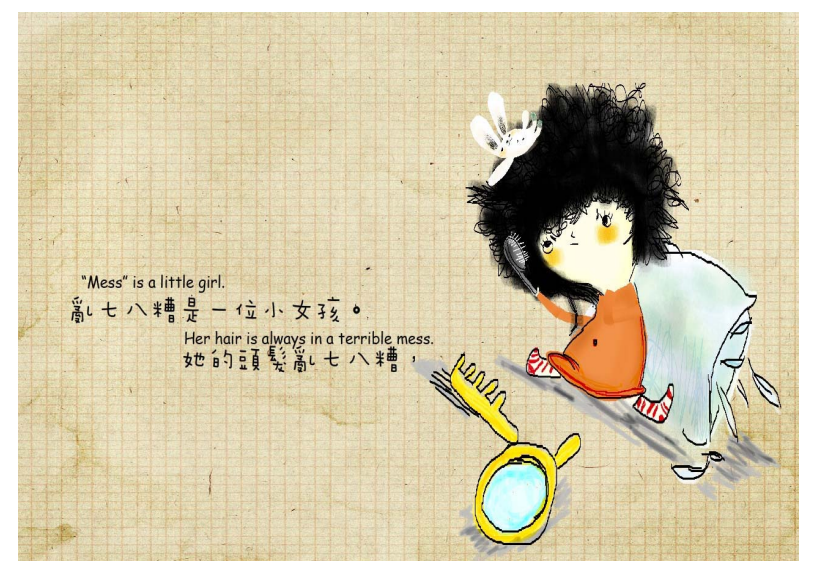

Figure 2.

A story animation made with Adobe Flash by one of the participants. teacher's teaching and clarify what are the best methods to integrate courseware and what circumstances are suitable for using digital material and what type of courseware are needed. Furthermore, the teacher also collected many types of courseware CD-ROMs which are published in the current market and analyzed their content and function. Through a discussion of the students' empirical field work and teacher's analysis of the current courseware, many tool kits for courseware integration have been clarified, such as storytelling, instructional presentations, student learning evaluations, drills, games and portfolio making. Consequently the teachers can demonstrate various practical examples of how to create the courseware. One of the students stated that this arrangement is very helpful for them in the design and organization of appropriate courseware.

We have learned a lot of multimedia editing skills, however it is still not clear to me how decide where to involve courseware, when to use it, and how to make it. Although we know how to use multimedia to create story picture books, classroom decorations, or work sheets, the other parts of the applications are very ambiguous for me. To go into the classroom and analyze the final product gives me a comprehensive direction and details of how to plan and make useful courseware.

With reference to this part the teacher commented that:

This process helps students to accumulate experience of integration, which can lead students to arranging and designing more appropriate digital tools to assist classroom teaching.

\section{Completing an Entire Courseware}

In this stage students learn how to make real courseware, which will include all the functions of a published CD-ROM. Firstly, the teacher introduces the interactive functions between the user and the computer interface and teaches students to write a simple computer program to control the digital elements in the scene; for which the ActionScript computer language in Adobe Flash CS3 was used. Through the control of ActionScript computer programming, students can easily produce an interactive interface by as clicking buttons, as shown in Figure 3. This function can allow users to teach interactively with students. Secondly, the teacher also demonstrates to students how to use Adobe Flash CS3 ActionScript to design the evaluation functions, such as true-false test and multiple-choice test, plus some games with drill functions correlated with the teaching topic, such as the jigsaw puzzle (shown in Figure 4), connect the dots, or the replacement game, etc. At this stage, some students declared their difficulty in learning due to their unfamiliarity and fear of computer programming. One student stated that:

When the teacher mentioned we had to learn computer programming, I felt very worried because we have not had this experience before. Although the teacher promised us that it would not be as difficult as we think, we were still very worried about whether we could handle it well.

Based on this point the teacher raised some strategies to improve the students' experience:

I understand clearly that they are concerned about writing computer programs. However, the control of the interactive functions needs no complicated computer programming and normally requires only one or two lines of code to be written, until we are designing games, which might become more complex. In that case, I select some games which are played frequently by children and provide the program and the codes for 


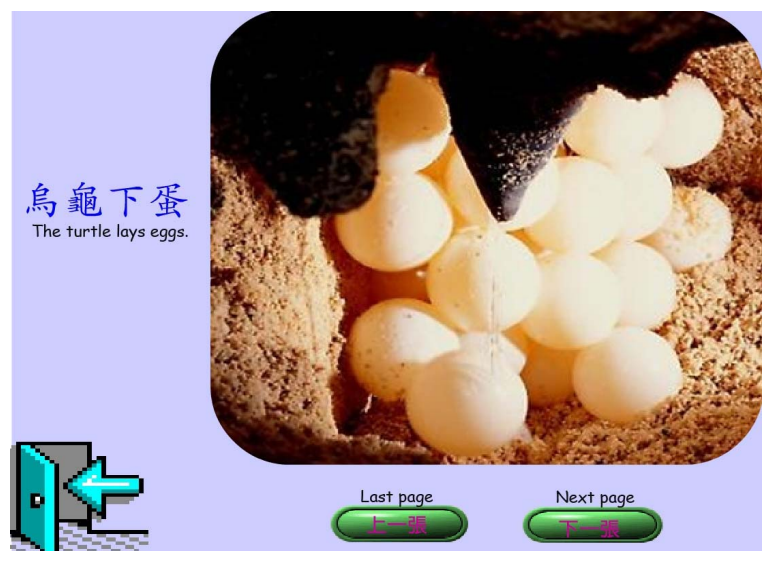

Figure 3.

An interactive interface controlled by clicking buttons.

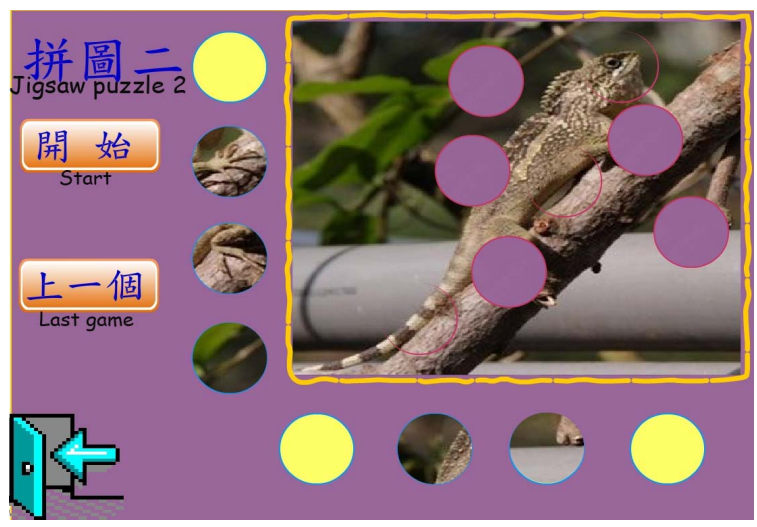

Figure 4.

A Jigsaw puzzle game related to the teaching topic "Reptilia".

the games. I do this to elucidate the principles of game design and demonstrate the meaning of each code. Based on the structure of these examples, what they have to do is to change the variables, the content and the background images. They can easily design a game which can fulfill their actual needs.

After practicing the control of a fundamental code, the teacher assigns a teaching theme to every student and asks them to develop an entire curriculum and produce digital courseware correlated to the theme. This teaching courseware has to involve the functions of instruction, drill, evaluation and game playing. All these functions and content are presented on the front page, as shown in Figure 5. The user only needs to click the selected button on the front page to go to the selected function. The completed courseware can be exported into an EXE file and burned to a CD. An instructional courseware has been completed, which is the same as a published CD-ROM courseware in the market.

\section{Reflection of the Whole Training Course}

At the end of the training course the whole training course was assessed, including the arrangement of the curriculum, teaching pedagogies, students' learning process and the presentation of the results. Most of the course participants agreed that they had greatly improved their professional development in multimedia technology. One of the students noted that:

I think I have improved a lot in the capacity of doing multi

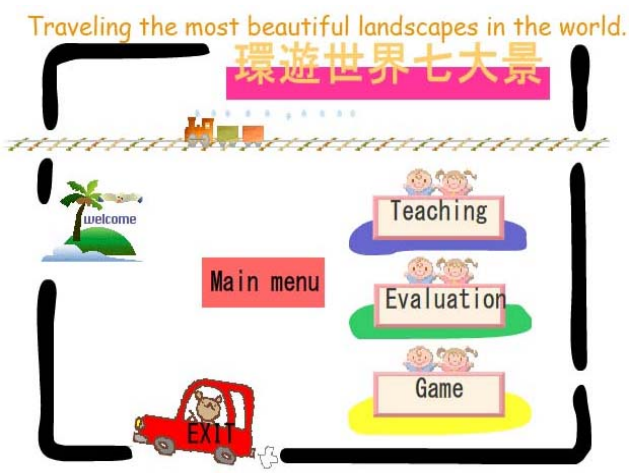

Figure 5.

A Front Page of a completed courseware in relation to world traveling.

media editing during this year's training. It is hard to believe that I can do digital photographic image editing, story animation, interactive functioning of an interface and simple game making. Before that I thought they were very difficult and very hard to learn. But now, through this series of courses, I am quite confident in dealing with them and can produce some digital products for classroom teaching.

\section{Another Student Also Claimed That}

I believe that these training courses were well arranged by the teachers. All the courses are well connected, and arranged in proper order from the basic to the advanced. The teachers not only taught us how to use the digital software but also taught us how to apply digital multimedia to the actual classroom teaching. Although our profession is early childhood education, we can complete a CD-ROM courseware at the end of our training. I agree that this project is quite successful.

However, a few of the students complained that to complete the homework was very time consuming. One of the students comments:

We have spent most of our time on this training course, but we still have other courses that need to be completed. Although we can handle what the teachers have requested, actually we have felt under stress during this training year.

The teacher responded on this point that:

In learning how to create courseware the students not only have to focus on knowing the techniques, but they also need to be able to operate practically by themselves. That is why the teacher has to arrange some specific task to lead the students through the practical aspects. Through the process of practice and manipulation they learn how to apply all the skills and become more familiar with using the software. So, in the initial stage they have to spend a lot of energy and time on the practical aspects. Once they have mastered this stage, they will have the freedom to do other kinds of work.

Many participants commented that this training course cultivated their capacity for successfully dealing with digital courseware design. They believe that it will help their professional development in the future and provide them with a variety of vocational alternatives.

\section{Discussion}

Through a series of training courses lasting two semesters and a long term qualitative data collection and analysis, the 
results show that pre-service teachers can be trained to be designers and producers of digital courseware in the absence of previous training in computer programming. Through this series of training programs they are now confident of being able to complete digital teaching material and courseware which is similar to the published CD-ROM in the present market.

However, some students did show their anxiousness and lack of confidence during the initial stage of the training course because they were unfamiliar with these computer technologies. Through the teachers' clarification and illustration of the logic and objectives of the whole curriculum to the student-learners, they gained sufficient understanding of the teaching content and pedagogy to reach an understanding of the learning process with the teacher. Most of the participants overcame their initial anxiety and engaged in the learning process and successfully completed the tasks by the end of the course. This finding coincides with Beckers and Schmidt (2003) and Beckers and Rikers's (2006) research that computer anxiety was found to correlate with students' perceptions of their own computer skills and experience.

Except for students' mental obstacles, the most critical factors which may influence the success of the training is the design and implementation of the curriculum. In this study, through a series of discussions with a number of experts in the field of early childhood education and multimedia, we decided on a series of training courses which can fit with pre-service teachers' level of computer technology and can fulfill the actual need of preschool classroom teaching. Therefore, the design of the training courses had to follow a sequence of learning logic and consider student's competency in using computers. The curriculum started from a fundamental course, such as computer graphics and image processing and progressed to the advanced courses such as the design of animation, interactive interface and simple games, and ended with the completion of a CDROM of courseware. This also indicated that proper learning strategies can help students to overcome their anxiety in learning new technology and achieve their learning goals (Namlu, 2003).

The evaluation of students' learning was based on the completion of students' work and a project provided by the teachers. Through the completion of homework tasks students can experience an entire process of making digital courseware. In addition, through the teachers' suggestions and feedback given in their work evaluation, students can accumulate more practical experience of making digital material and create more mature work for their future needs in classroom teaching.

This study was designed to cultivate pre-service teachers' professional ability in applying multimedia, and thus greatly differs from the traditional training course. Typically, in Taiwan, this type of training course is used for in-service teachers and normally is designed to be of just a few hours' duration or a one day workshop. The content of these courses is limited to the transmission of the principles and theories of how to integrate technology and sometimes there is a demonstration of how it works. It is very rare for the actual practice of making digital courseware to be approached. There is a need to fill the gap between theory and practice and help teachers to improve their ability in using multimedia technology (Keengwe \& Onchwari, 2009). Therefore, it is essential to train and equip teachers with the skills necessary to improve their ability in the integration of technology (Keengwe, 2007). In fact, teachers still play the role of user in the integration of multimedia in classroom teaching. Teachers could not make courseware for themselves and although they preferred to spend a lot of effort and time in searching for and selecting suitable digital material for their teaching, they frequently found that the materials did not exactly fit their actual needs. This situation creates a lot of obstacles for teachers in the process of technology integration. Therefore, a teacher's role should be promoted from the user to the designer in order to create the digital courseware which can actually fulfill their teaching needs. Through a series of training courses during their teacher-training period, teachers can become courseware designers and will have the capacity and experience to integrate and produce multimedia courseware in their future classroom teaching.

\section{Conclusion}

Integration of digital multimedia in classroom teaching is not just a slogan or a concept to be understood. Instead, it is the implementation of computer technology in combination with teaching and learning. Through the rapid development of computer technology various digital courseware and teaching aids are developed and have evolved swiftly. However, these designed coursewares do not normally fit the teachers' needs completely because most of the designers are not teachers who actually teach in the classroom. Teachers can only select and adopt some related and useful digital material from the published market, which causes an inefficient and ineffective integration in classroom teaching. In order to resolve this awkward situation, the time for teachers to become courseware designers has arrived. They are no longer just playing the passive role of "a user" but an active role of "a creator".

One condition to be overcome for teachers to become designers is to develop their ability to use multimedia technology. But the traditional training course, seminar and workshop are too brief and do not provide enough detailed information to train teachers to become courseware designers. Only a series of multimedia training courses and long term training can develop teachers to become practical courseware designers during their teacher training period. Therefore, this study aims to provide an insight into the experience of a group of pre-service teachers during a year of digital technique training through a series of courseware designing courses. This study shows that pre-service teachers can be trained to be courseware designers capable of planning and producing sufficient digital courseware which can fulfill teachers' classroom teaching needs. This study has also demonstrated an adequate training course and pattern to train teachers to be courseware producers; an experience which can be referenced by other teacher training institutions. This result has broken the barrier that defined the production of multimedia teaching aids or courseware as the domain of the engineer or computer programmer, it is now within the domain of the qualified school teacher. We also advocate that the role of teacher-user should be promoted to the role of teacher-designer.

\section{REFERENCES}

Baylor, A. L., \& Ritchie, D. (2002). What factors facilitate teacher skill, teacher morale, and percived student learning in technology-using classroom? Computers \& Education, 39, 395-414. doi:10.1016/S0360-1315(02)00075-1

Becker, H. J. (2000). Who's wired and who's not: Children's access to and use of computer technology. The Future of Children: Children and Computer Technology, 10, 44-75. doi:10.2307/1602689 
Beckers, J. J., Rikers, R. M. J. P., \& Schmidt, H. G. (2006). The influence of computer anxiety on experienced computer users while performing complex computer tasks. Computers in Human Behavior, 22, 456-466. doi:10.1016/j.chb.2004.09.011

Beckers, J. J., \& Schmidt, H. G. (2003). Computer experience and computer anxiety. Computers in Human Behavior, 19, 785-797. doi:10.1016/S0747-5632(03)00005-0

Culp, K. M., Honey, M., \& Mandinach, E. (2005). A retrospective on twenty years of educational technology policy. Journal of Educational Computing Research, 32, 279-307. doi:10.2190/7W71-QVT2-PAP2-UDX7

Denzin, N. K., \& Lincoln, Y. S. (1998). The landscape of qualitative research: Theories and issue. London: Sage Publications.

Dick, W., \& Carey, L. (1996). The systematic design of instruction (4th ed.). New York: Harper Collins.

Dodge, B. (1997). WebQuest taxonomy: Ataxonomy of tasks. URL (last checked 3 November 2012). http://edweb.sdsu.edu/courses/edtec596

Galanouli, D., Murphy, C., \& Gardner, J. (2004). Teachers’ perceptions of the effectiveness of ICT-competence training. Computers \& Education, 43, 63-79. doi:10.1016/j.compedu.2003.12.005

Harris, J. (2005). Our agenda for technology integration: It's time to choose. Contemporary Issues in Technology and Teacher Education, 5, 116-122

Heinich, R., Molenda, M., Russell, J. D., \& Smaldino, S. E. (2001). Instructional media and technologies for learning (7th ed.). Englewood Cliffs, NJ: Prentice Hall.

Keengwe, J. (2007). Faculty integration of technology into instruction and students' perceptions of computer technology to improve student learning. Journal of Information Technology Education, 6, 169-180.

Keengwe, J., \& Onchwari, G. (2009). Technology and early childhood education: A technology integration professional development for practicing teachers. Early Childhood Education Journal, 37, 209-218. doi:10.1007/s10643-009-0341-0

Mayer, R. E. (2005). The Cambridge handbook of multimedia learning. Cambridge: Cambridge University Press.
doi:10.1017/CBO9780511816819

Mayer, R. E., Heiser, J., \& Lonn, S. (2001). Cognitive constraints on multimedia learning: When presenting more material results in less understanding. Journal of Educational Psychologist, 93, 187-198. doi:10.1037/0022-0663.93.1.187

Namlu, A. G. (2003). The effect of learning strategy on computer anxiety. Computers in Human Behavior, 19, 565-578. doi:10.1016/S0747-5632(03)00003-7

Palak, D., \& Walls, R. T. (2009). Teachers' beliefs and technology practices: A mixed methods study. Journal of Research on Technology in Education, 41, 417-441. doi:10.1111/j.1365-2729.2005.00120.x

Sime, D., \& Priestley, M. (2005). Student teachers' first reflections on information and communciations technology and classroom learning: Implications for initial teacher education. Journal of Computer Assisted Learning, 21, 130-142. doi:10.1080/13674580701687807

Slaouti, D., \& Barton, A. (2007). Opportunities for practice and development: Newly qualified teachers and the use of information and communications technologies in teaching foreign languages in English secondary school contexts. Journal of In-Service Education, 33, 405-424.

Tsai, S. C. (2010). Developing and integrating courseware for oral presentations into ESP learning contexts. Computers \& Education, 55, 1245-1258. doi:10.1016/j.compedu.2010.05.021

Volman, M. (2005). A variety of roles for a new type of teacher educational technology and the teaching profession. Teaching and Teacher Education, 21, 15-31. doi:10.1016/j.tate.2004.11.003

Wang, Q., \& Woo, H. L. (2007). Systematic planning for ICT integration in topic learning. Educational Technology \& Society, 10, 148156.

Wilson, (1999). Evolution of learning technologies: From instructional design to performance support to network systems. Educational Technology, 39, 32-35.

Wozney, L., Venkatesh, V., \& Abrami, P. (2006). Implementing computer technologies: Teachers' perceptions and practices. Journal of Technology and Teacher Education, 14, 173-207. 